\title{
MICROCLIMAS E VEGETAÇÃO NO BAIXO VALE DO RIO MASCATES E CÓRREGO DA SERRA, PQ. NACIONAL DA SERRA DO CIPÓ-MG
}

\author{
Carlos Henrique Jardim ${ }^{(a)}$ \\ (a) Docente, Depto. Geografia/IGC, UFMG, dxhenrique@gmail.com
}

Eixo: Climatologia em Diferentes Níveis Escalares: Mudanças e Variabilidades

\begin{abstract}
Resumo
O presente artigo analisa a influência da vegetação nas variações de temperatura e umidade relativa do ar em área interior do Pq. Nacional da Serra do Cipó. Os dados foram produzidos continuamente em intervalo horário por períodos de dois a quinze dias consecutivos, entre os anos de 2012 e 2016. A análise considerou a relação dos dados mensurados com as características físicas do ambiente (relevo e vegetação) sob condições atmosféricas diferenciadas e os resultados mostraram grau diferenciado de comprometimento com fatores naturais.
\end{abstract}

Palavras chave: vegetação, cerrado, microclimas.

\section{Introdução}

O interesse no desenvolvimento da temática aqui apresentada relaciona-se em compreender o papel dos fatores naturais, notadamente a vegetação, tomando como área de estudo trecho interior do Parque Nacinal da Serra do Cipó. Embora conste de inúmeras referências, principalmente na área de botânica, inclusive de pesquisas realizadas no século 19 conforme cita Gontijo (2008), há várias lacunas no que diz respeito a outras áreas do conhecimento, como a climatologia. O próprio plano de manejo do Pq. Nacional da Serra do Cipó (MMA-ICMBIO, 2009) contempla essa informação de forma muito generalizada.

A relação entre clima e vegetação está longe de ser esgotada e pode fornecer inúmeros subsídios para o planejamento urbano e questões ambientais. Atualmente essa relação é muito explorada em pesquisas de clima urbano, clima e arquitetura e, inclusive, como suporte para estudos de impactos ambientais e planos de manejo em unidades de conservação.

No caso específico da área em questão, a vegetação é um dos principais componentes organizadores dos espaços microclimáticos, dividindo esse papel, em termos de importância, com a topografia. Em relação ao Parque Nacional da Serra do Cipó isso fica evidente pela verificação de imagens de satélite e/ou fotografias aéreas e ao percorrer suas trilhas, no qual é possível distinguir inúmeras fitofisionomias de cerrado, mata ciliar e formações rupestres, todas relativamente preservadas e/ou em diferentes estágios de recomposição. 
Mesmo no interior dos domínios de uma unidade de conservação, isso não significa ausência de influência antrópica. A própria visitação pública implica em impactos ambientais: formação de ravinas associada ao pisoteio e compactação dos solos favorecendo a concentração de águas de escoamento superficial, disposição inadequada de lixo, interferência na vida animal etc.

Outra categoria de impactos ambientais diz respeito à proximidade com áreas urbanas e rurais que, no caso do Parque Nacional da Serra do Cipó, faz limites com seis municípios (Jaboticatubas, Santana do Riacho, Morro do Pilar, Itambé do Mato Dentro, Nova União e Itabira). Embora a área urbana desses municípios seja reduzida, a área rural é expressiva e parte do que se produz nesses espaços (calor, material particulado etc.) pode ser transportado pelo vento conforme corroboram inúmeros trabalhos.

Isso tudo deveria constituir-se em aviso para que mais atenção por parte das autoridades públicas fosse dispendida às unidades de conservação no sentido de implementar e adequar os planos de manejo às realidades locais e regionais, implantação de programas efetivos de educação ambiental e melhoria na administração e fiscalização.

Para elaboração deste artigo foram retomados alguns trabalhos produzidos a partir de mensurações no interior do parque (MACHADO et al., 2014a; MACHADO et al., 2014b; FIGUEIREDO et al. 2014), apoiados em tomadas pontuais restritas há 02 ou 03 dias seguidos de mensurações. Embora o foco seja similar, apoiado na interação entre a atmosfera e os conroles naturais em superfície, através de dois de seus principais atributos (temperatura e umidade relativa do ar) com os componentes dos demais subsistemas terrestres (vegetação, relevo e fatores antrópicos), esta pesquisa conta com tomadas horáriodiárias contínuas de 25 dias consecutivos divididos em dois períodos (entre 29/04 a 08/05/2016 e entre 10 e 24/09/2016), o que permitiu explorar de forma mais efetiva a relação com o controle atmosférico, através da identificação dos sistemas atmosféricos e tipos de tempo. A compreensão dessas interações é fundamental para se avaliar o impacto do clima sobre o ambiente (intensidade, frequência e duração dos eventos climáticos).

A área escolhida para compreensão dessas relações incluiu parte do alto vale do rio Cipó, em trecho de área drenada por dois de seus formadores, o rio Mascates e o córrego da Serra, no interior da unidade de conservação do Pq. Nacional da Serra do Cipó (figura 1). Trata-se de uma das mais importantes áreas de proteção ambiental em porção interior do estado de Minas Gerais para preservação de ecossistemas e manutenção de processos naturais.

Situado no Planalto Meridional da Serra do Espinhaço, conforme denominação de Saad (1995), a complexidade geológico-geomorfológica em interação com aspectos biogeográficos e climáticos induzidos pelo efeito orográfico, confere a esse espaço aspectos de unicidade em termos de organização 


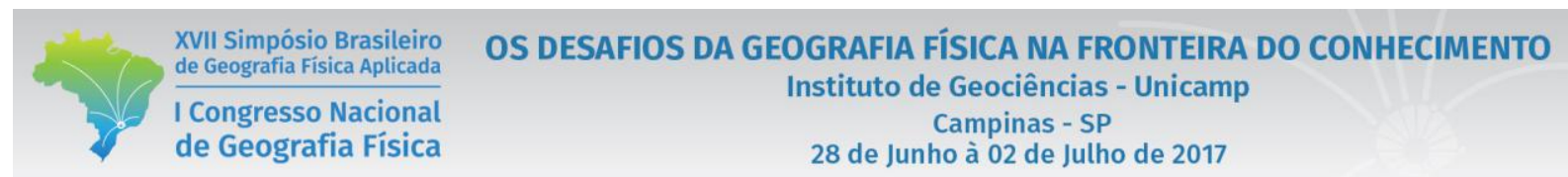

da paisagem, denunciados pela ocorrência de espécies endêmicas e preservação de elementos relictuais. Diferentemente de amplas áreas de topografia plana, o relevo escarpado, com morros e vales profundamente entalhados, assume papel relevante na organização de topoclimas e biótopos florestais, visível pela diversidade de ambientes ao se percorrer as trilhas do parque.

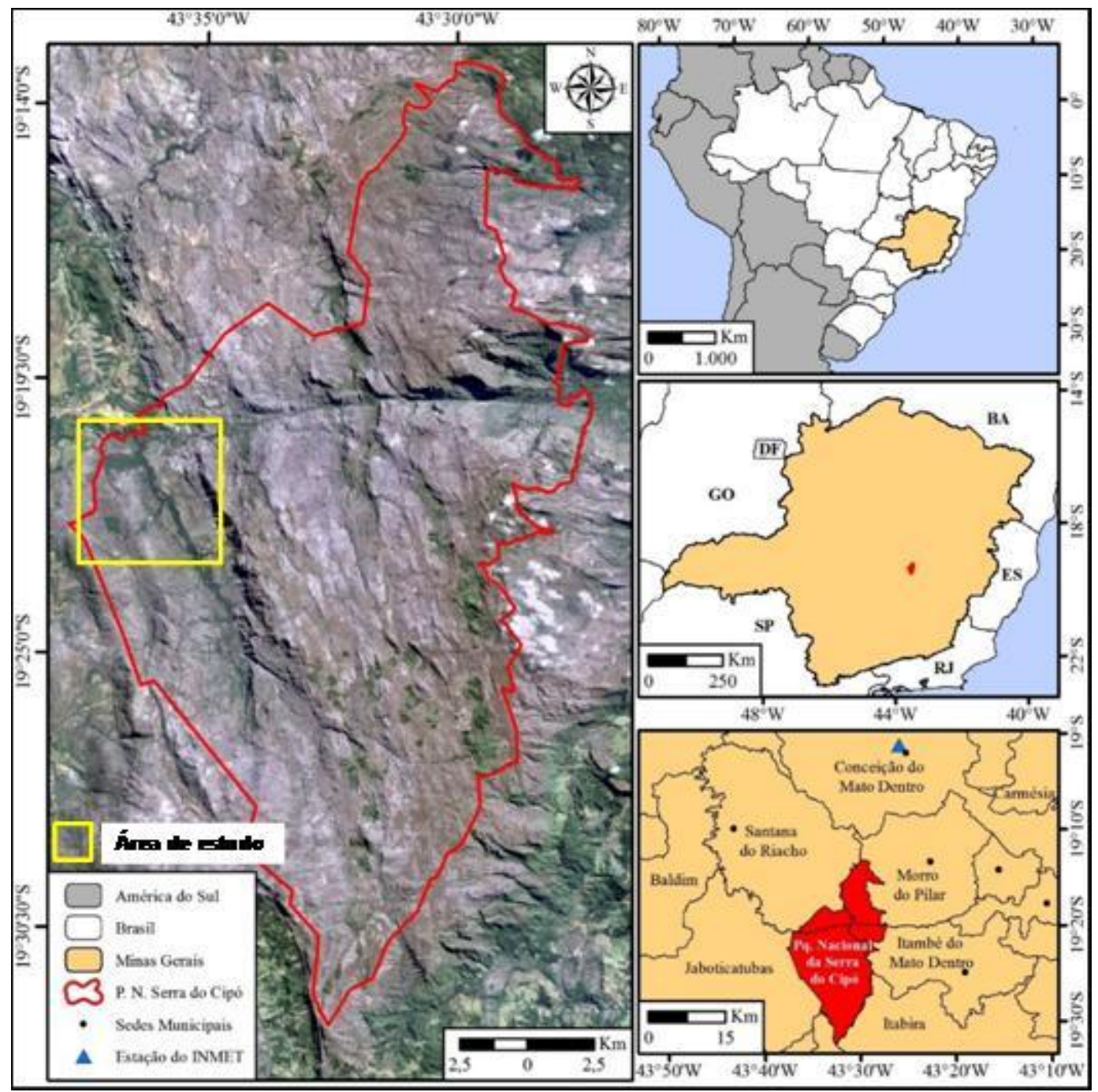

Figura 1 - Localizaçao da área de estudo (baixo vale do rio Mascates e córrego da Serra) no interior do Pq. Nacional da Serra do Cipó. Fontes: Google Maps (2016); IBGE (2016). Elaboração: Aion Angelu Ferraz Silva.

O objetivo deste artigo é caracterizar a influência exercida pelos diferentes fatores naturais nas variáveis do clima, notadamente o papel da vegetação, um dos principais componentes de organização de espaços microclimáticos na Serra do Espinhaço, e sua relação com o desempenho térmico e higrométrico do ar (temperatura e umidade relativa). A quase total ausência de trabalhos dessa natureza na área escolhida 


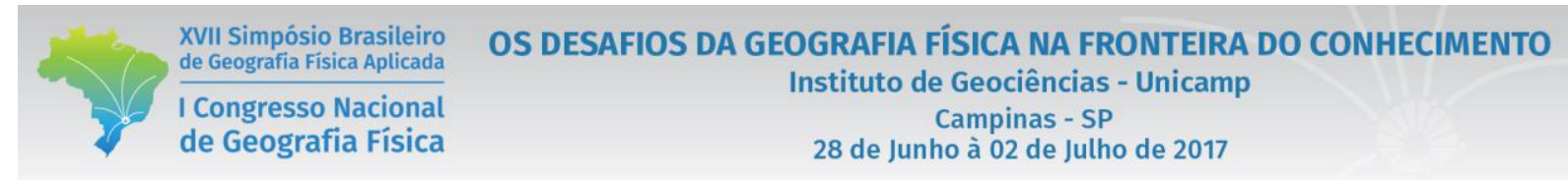

como objeto de estudo, além de sua importância como indicador de alterações ambientais, justificam em grande medida a implementação desta pesquisa.

\section{Materiais e Métodos}

O equipamento básico utilizado para mensuração de dados de temperatura e umidade relativa do ar foi o registrador automático datalogger modelos HT 500 e HT 4000 (figura 2), programados para leituras horárias. $\mathrm{O}$ equipamento foi disposto em abrigo meteorológico projetado para esse fim e aferido com a estação meteorológica do INMET Belo Horizonte - Pampulha, situada no campus da UFMG. Após a aferição foi feita a correção dos valores obtidos a fim de tornar os dados obtidos comparáveis àqueles das estações meteorológicas oficiais do INMET utilizadas, também, como controle local das variáveis climáticas.
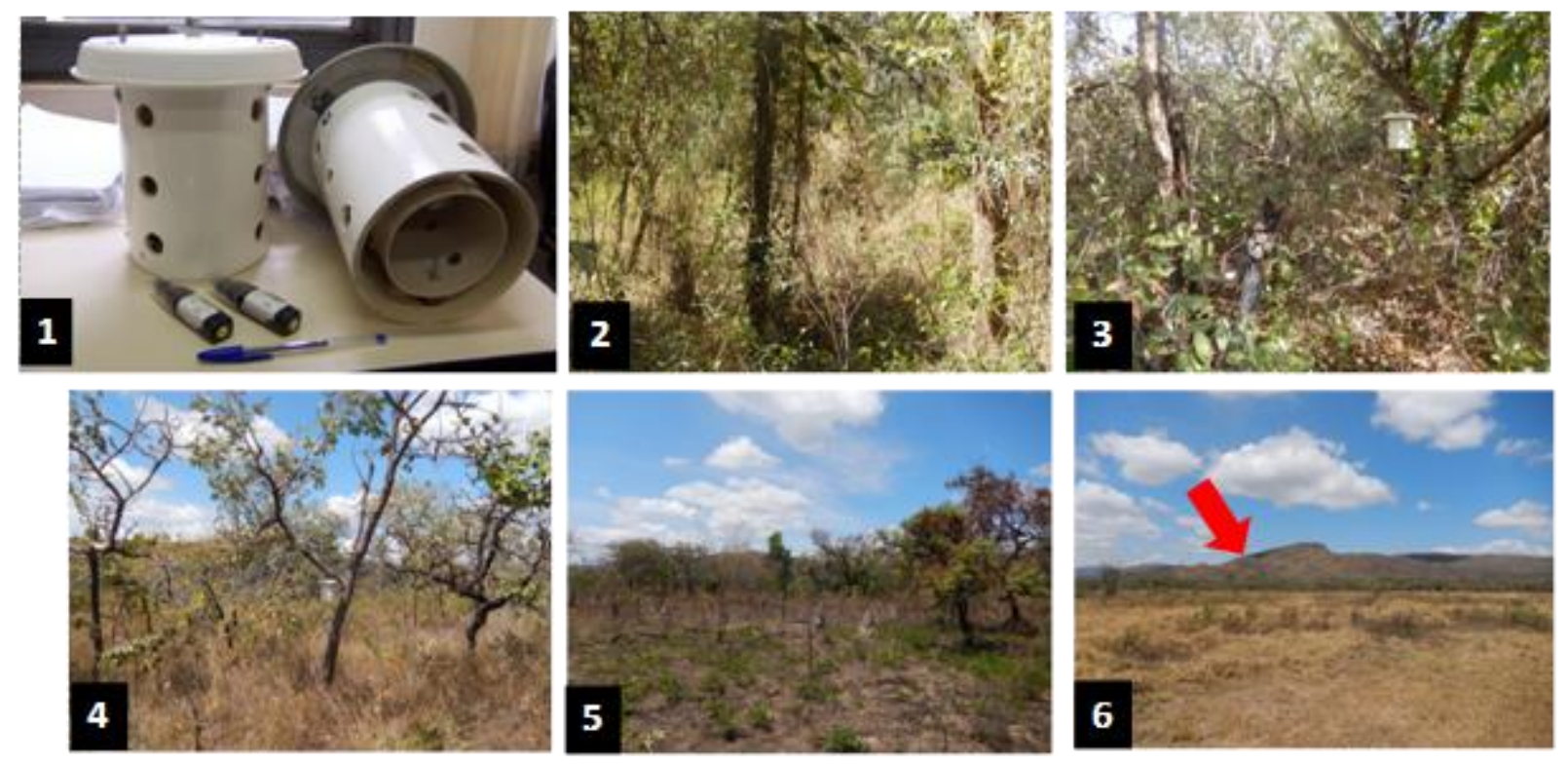

Figura 2 - Características dos equipamentos e locais de mensuração: 1. registradores e abrigo; 2. Mata ciliar na confluência dos rios Bocaina-Mascates; 3. Cerrado Arbóreo; 4. Cerrado do Alto Capão; 5. Cerrado em área de recomposição vegetal; 6. Mirante do Bem (posição do posto na vertente indicada pela seta). Fotos: Carlos H. Jardim.

Os períodos de coleta de dados compreenderam, principalmente, dois segmentos temporais totalizando 25 dias: entre 29/04 a 08/05/2016 (10 dias) e entre 10 e 24/09/2016 (15 dias). Os postos foram distribuidos no inteior da área de estudo (figuras 2 e 3) de forma a obter comparações entre áreas dotadas de diferentes características de topografia e cobertura vegetal e, assim, verificar através das variações dos atributos climáticos o impacto desigual da distribuição de energia solar e calorífica no ambiente, modulada pelos diferentes fatores de superfície. Para isso, contou-se com cinco postos (figuras 2 e 3): (1) Mata ciliar na 


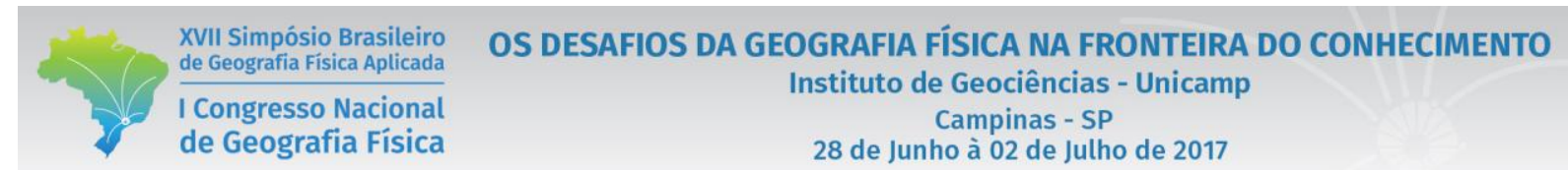

confluência dos rios Bocaina-Mascates (altitude: 802 m; 19²0’50,40” S e 43³6’20,70” W); (2) Cerrado - área com presença de estratos herbáceo e arbóreo equitativamente distribuídos (altitude: 802 m;

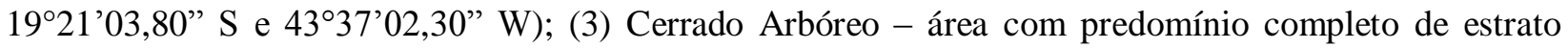
arbóreo (altitude: $811 \mathrm{~m} ; 1^{\circ} 21^{\prime} 05,90^{\prime}$ S e 4336’33,90" W); (4) Mirante - topo de colina em meio a

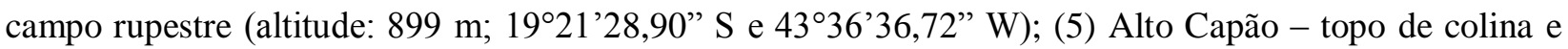
cerrado típico sobre latossolos (altitude: 986 m; 19²2’04,10” S e 4337’03,90” W).

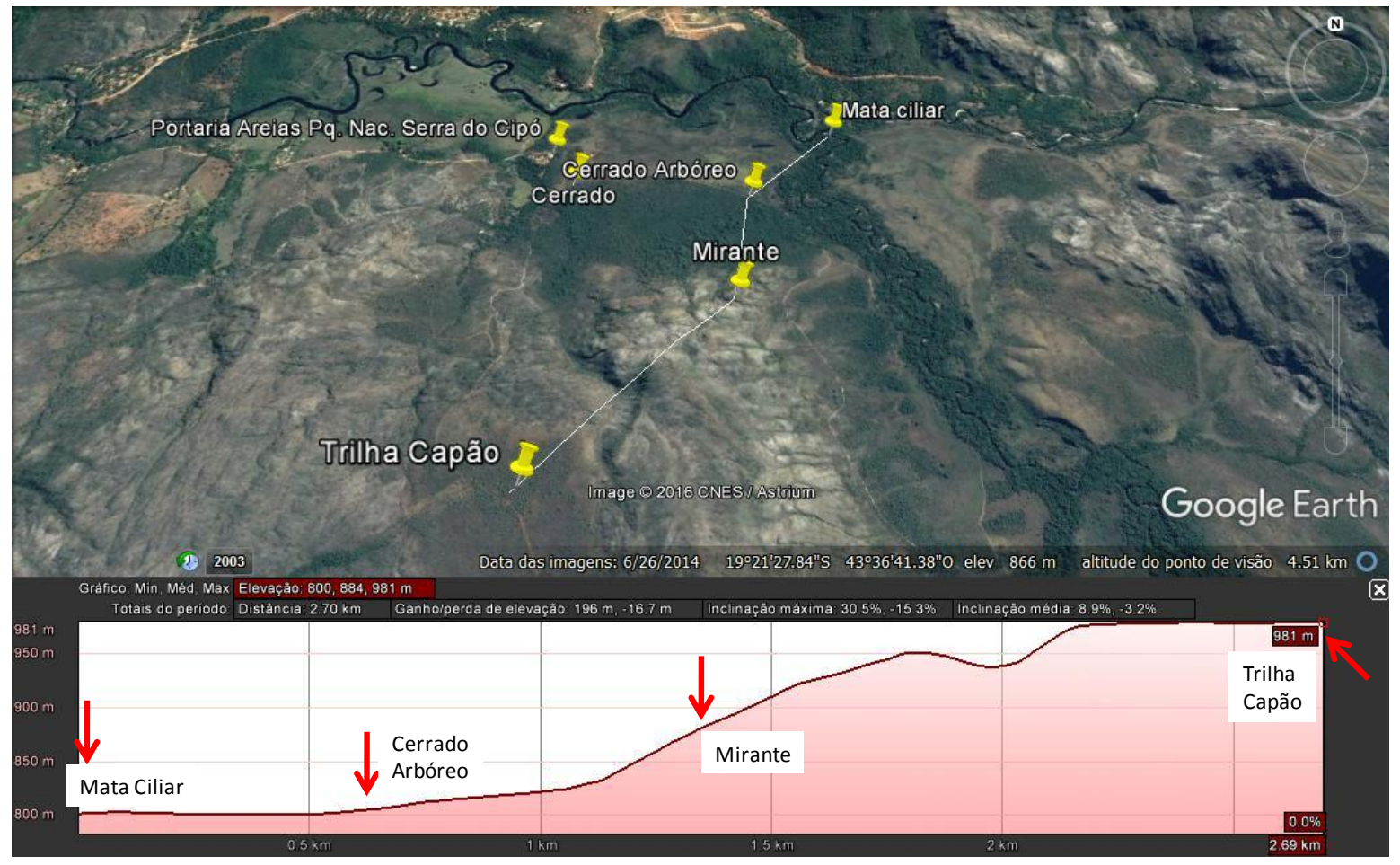

Figura 3 - Distribuição dos postos no interior da área de estudo no Pq. Nacional da Serra do Cipó, trecho inferior da bacia do rio Mascates e córrego da Serra, alto curso do rio Cipó. Fonte: Google Earth, 2017. Elaboração: Carlos H.

Jardim

As séries de dados horários de temperatura e umidade relativa foram analisadas de forma comparativa, pautada na relação entre as variáveis mensuradas (temperatura e umidade relativa do ar) com os fatores de superfície (vegetação e topografia) e atmosféricos através da sucessão dos tipos de tempo (inferidos pela ação dos sistemas atmoféricos ou massas de ar). Optou-se pela elaboração dos gráficos considerando a representação contínua e simultânea dos elementos climáticos com os sistemas atmosféricos (repercussão espacial do sistema atmosférico atuante) considerando os critérios da análise rítmica (MONTEIRO, 1971).

A sucessão dos tipos de tempo foram definidos a partir da análise de imagens de satélite e cartas sinóticas (www.cptec.inpe.br; www.mar.mil.br) e as diferenças (ou não) nos valores expressos pelos elementos 


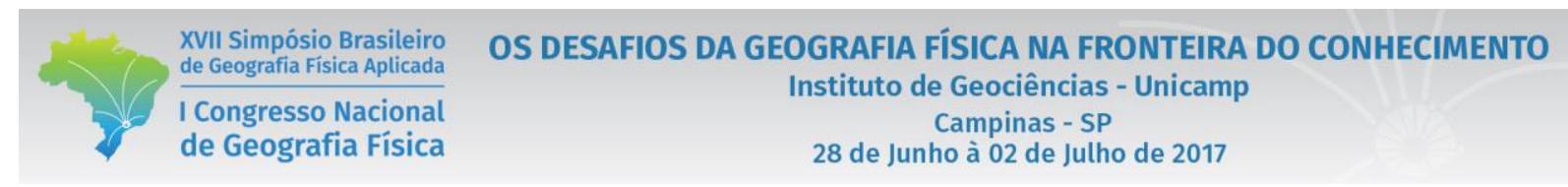

climáticos foram admitidos como representativos de variações naturais, dada pela interações com fatores ambientais, e como indícios de alterações ambientais, podendo trazer consequiências para as organizações ambientais dependendo da frequência, intensidade e duração do evento, que são respostas à entrada, permanência e transito de energia no sistema-ambiente.

O material bibliográfico consultado para conferir suporte às análises, além daqueles citados anteriormente, incluiu fontes documentais diversas (dissertações, teses, livros, artigos etc.) destacando-se o plano de manejo do Parque Nacional da Serra do Cipó (MMA-ICMBIO, 2009) e temas ligados à microclimatologia (GEIGER, 1961; AZEVEDO, 2001; TARIFA, 2001; TARIFA e ARMANI, 2001; BONAN, 2008).

\section{Resultados}

Diferentes fatores influenciaram as variações da temperatura e umidade relativa do ar. No caso do posto do Mirante, os valores de temperatura mostraram-se mais elevados em relação aos demais postos no período entre 06 e 08/05 e, portanto, com menores valores de umidade relativa do ar. Os valores médios de variação dos atributos nesse posto (tabela I) assinalaram $3,3^{\circ} \mathrm{C}$ superior em relação ao posto da mata ciliar $\left(21,8^{\circ} \mathrm{C}\right.$ e $\left.18,7^{\circ} \mathrm{C}\right)$ e $2,5^{\circ} \mathrm{C}$ superior ao valor do posto do Alto Capão $\left(21,8^{\circ} \mathrm{C}\right.$ e $\left.19,3^{\circ} \mathrm{C}\right)$. Em relação à umidade relativa, respectivamente, os valores assinalados foram inferiores em 14,5\% (58\% e 72,5\%) e $7,3 \%(58 \%$ e $65,3 \%)$.

Três fatores tiveram participação efetiva nas variações dos atributos: orientação de vertente N-NE (nortenordeste), cobertura vegetal com predominância de elementos arbustivo-herbáceo de baixo recobrimento foliar e presença de solos rasos com fragmentos e afloramentos de rocha, típico de campo rupestre.

Tabela I - Valores médios de temperatura e umidade relativa do ar: 06-08/05/2016 e 10-24/09/2016

\begin{tabular}{|c|c|c|c|c|c|c|c|c|c|c|}
\hline & \multicolumn{2}{|c|}{ Alto Capão } & \multicolumn{2}{|c|}{ Cerrado Aberto } & \multicolumn{2}{|c|}{ Cerrado Arbóreo } & \multicolumn{2}{|c|}{ Mata Ciliar } & \multicolumn{2}{|c|}{ Mirante } \\
\hline Períodos & Temp. $\left({ }^{\circ} \mathrm{C}\right)$ & UR (\%) & Temp. $\left({ }^{\circ} \mathrm{C}\right)$ & UR (\%) & Temp. $\left({ }^{\circ} \mathrm{C}\right)$ & UR (\%) & Temp. $\left({ }^{\circ} \mathrm{C}\right)$ & UR (\%) & Temp. $\left({ }^{\circ} \mathrm{C}\right)$ & UR (\%) \\
\hline $06-08 / 05 / 2016$ & 19,3 & 65,3 & 18,7 & 69,2 & $x$ & $x$ & 18,5 & 72,5 & 21,8 & 58,0 \\
\hline $10-24 / 09 / 2016$ & 23,3 & 47 & 24 & 48 & 23,7 & 48 & 23,6 & 49 & $x$ & $x$ \\
\hline
\end{tabular}

No primeiro caso, o componente norte (N, NE e NW) de orientação da vertente garante maior carga de insolação em relação aquelas de orientação com componente sul (S, SW e SE), decorrente da própria trajetória aparente do Sol no hemisfério sul, cujo efeito é maior se aliado à declividade da vertente. Neste caso o ângulo de incidência da radiação solar está mais próximo de $90^{\circ}$ do que sobre os segmentos planos dessa vetente onde está o posto, o que implica em maior ganho de radiação por unidade de área (quanto 
mais próximo de $90^{\circ}$, menor a área de recpção de energia em relação ao fluxo de radiação solar, que é o mesmo para a ampla área do parque, considerando a variação exígua de latitude).

O elevado saldo de radiação é reforçado pela fraca cobetura foliar da vegetação que expõe grande parte da superfície à insolação durante todo o período. A carga de radiação que atinge essa superfície não encontra condições de propagar-se em profundidade ficando retida nos primeiros centímentros superficiais, numa mescla de solos com vegetação esparça e presença de elementos litólicos, inclusive na forma de afloramentos de rocha com baixo valor de calor específico e baixa capacidade calorífica, principalmente quando estão secos, ou seja, ao mesmo tempo em que pode experimentar forte resfriamento, alcança valores muito alevados de temperatura durante o dia, tranferindo para o ar e ambiente circunjacente o calor produzido.

O posto do Alto Capão apresentou elevada amplitude térmica, aproximando-se das temperaturas mais elevadas registradas nos postos do Mirante e do Cerrado durante o dia e, ao mesmo tempo, aproximandose dos valores mais baixos registrados no posto da Mata Ciliar no período noturno (tabela II e figura 4). Essa caracterítica está atrelada ao baixo recobrimento foliar da vegetação, que permite entrada da radiação incidente durante o dia (semelhante ao posto do cerrado), e ao fator altitude, cuja influência transparece de forma efetiva no período noturno, tanto no que se refere ao efeito de resfriamento por descompressão adiabática quanto pela forte dissipação de calor promovida pela advecção de ar associada à circulação local e regional que afeta áreas topograficamente mais elevadas.

Isso, inclusive, afetou os valores médios diários de temperatura desse posto, garantindo menor valor no segundo período de mensurações (tabela II e figura 4) comparativamente aos demais postos $\left(23,4^{\circ} \mathrm{C}\right.$ contra $23,7^{\circ} \mathrm{C}$ da Mata Ciliar). As condições atmosféricas estáveis (ar muito seco e pouca nebulosidade) nesse segundo período de mensurações (11 a 23/09) aceleraram a perda de calor, decorrente do reduzido efeito estufa natural (lembrando que o vapor d'água é o principal gas de efeito estufa atmosférico).

O posto da mata ciliar exibiu os mais baixos valores médios no primeiro período de mensurações (tabela I), embora tenha ficado atras do posto do Alto Capão no segundo período (tabela II). A presença de vegetação, neste caso com predomínio completo de elementos de porte arbóreo e arborecente, solos recobertos por serrapilheira e proximidade em relação ao curso d'água (confluência dos rios Bocaina e Mascates), propicia baixo saldo radiativo (predomínio do componente difuso de radiação solar) e, portanto, condições efetivas de sombreamento. A baixa condutividade térmica pelo ambiente, também é outro fator a ser levado em consideração. Segundo Geiger (1961, p. 268), a capacidade calorífica da massa do povoamento (referindo-se à vegetação) é $0,8 \mathrm{cal} / \mathrm{cm}^{2}{ }^{\circ} \mathrm{C}$. Portanto, superior ao do concreto $(0,2$ $\left.\mathrm{cal} / \mathrm{cm}^{2} .{ }^{\circ} \mathrm{C}\right)$ e próxima a da água $\left(1,0 \mathrm{cal} / \mathrm{cm}^{2} .{ }^{\circ} \mathrm{C}\right)$. 
Tabela II - Valores médios diários de temperatura e umidade relativa do ar: 30/04-07/05/2016 e 11-23/09/2016

\begin{tabular}{|c|c|c|c|c|c|c|c|c|}
\hline & Capão & Cerrado & Mata Ciliar & & Capão & Cerrado & Mata Ciliar & Cerrado Arbóreo \\
\hline $30 / a b r$ & 18,3 & 18,8 & 18,0 & 11 set & 22,3 & 23,0 & 22,4 & 22,7 \\
\hline $01 / \mathrm{mai}$ & 20,4 & 20,5 & 18,8 & $12 /$ set & 23,2 & 23,2 & 22,6 & 23,1 \\
\hline $02 / \mathrm{mai}$ & 19,0 & 19,4 & 18,4 & $13 /$ set & 23,7 & 24,4 & 23,8 & 24,1 \\
\hline 03/mai & 19,3 & 19,9 & 19,2 & $14 /$ set & 25,7 & 25,9 & 25,4 & 25,4 \\
\hline 04/mai & 19,6 & 19,6 & 18,5 & $15 /$ set & 27,3 & 27,4 & 26,7 & 27,1 \\
\hline $05 / \mathrm{mai}$ & 20,7 & 21,1 & 19,4 & $16 /$ set & 23,4 & 24,4 & 24,2 & 24,2 \\
\hline $06 / \mathrm{mai}$ & 19,9 & 20,0 & 19,4 & $17 /$ set & 22,3 & 23,2 & 23,1 & 23,1 \\
\hline \multirow[t]{6}{*}{$07 / \mathrm{mai}$} & 20,5 & 20,0 & 19,6 & $18 /$ set & 23,9 & 24,2 & 24,3 & 23,9 \\
\hline & & & & $19 /$ set & 25,1 & 26,0 & 25,6 & 25,4 \\
\hline & & & & $20 /$ set & 24,3 & 25,6 & 25,1 & 25,1 \\
\hline & & & & $21 /$ set & 21,7 & 22,4 & 22,1 & 22,0 \\
\hline & & & & $22 /$ set & 19,1 & 20,0 & 19,6 & 19,7 \\
\hline & & & & $23 /$ set & 22,6 & 23,6 & 22,9 & 23,2 \\
\hline \multirow[t]{2}{*}{ Média } & 19,7 & 19,9 & 18,9 & Média & 23,4 & 24,1 & 23,7 & 23,8 \\
\hline & Capão & Cerrado & Mata Ciliar & & Capão & Cerrado & Mata Ciliar & Cerrado Arbóreo \\
\hline $30 / a b r$ & 79 & 78 & 84 & $11 /$ set & 47 & 46 & 46 & 44 \\
\hline $01 / \mathrm{mai}$ & 69 & 71 & 79 & $12 /$ set & 45 & 44 & 43 & 39 \\
\hline $02 / \mathrm{mai}$ & 66 & 66 & 71 & $13 /$ set & 44 & 43 & 43 & 42 \\
\hline 03/mai & 63 & 63 & 68 & $14 /$ set & 39 & 39 & 39 & 35 \\
\hline $04 / \mathrm{mai}$ & 61 & 64 & 71 & $15 / \mathrm{set}$ & 38 & 37 & 38 & 32 \\
\hline $05 / \mathrm{mai}$ & 62 & 63 & 71 & $16 /$ set & 50 & 50 & 49 & 50 \\
\hline $06 / \mathrm{mai}$ & 63 & 66 & 70 & $17 /$ set & 55 & 55 & 55 & 56 \\
\hline \multirow[t]{6}{*}{$07 / \mathrm{mai}$} & 63 & 67 & 71 & $18 /$ set & 54 & 55 & 55 & 52 \\
\hline & & & & $19 /$ set & 50 & 50 & 51 & 49 \\
\hline & & & & $20 /$ set & 51 & 51 & 52 & 52 \\
\hline & & & & $21 / \mathrm{set}$ & 56 & 56 & 56 & 56 \\
\hline & & & & $22 / \mathrm{set}$ & 56 & 55 & 55 & 57 \\
\hline & & & & $23 /$ set & 49 & 48 & 48 & 48 \\
\hline Média & 66 & 67 & 73 & Média & 49 & 48 & 48 & 47 \\
\hline
\end{tabular}

Objetos dotados de elevado valor de calor específico precisam ganhar muita energia para experimentar alguma elevação de temperatura. Neste caso, esse fator associado à proximidade do posto em relação ao rio, que é uma fonte adicional de umidade (ausente nos demais postos), atenua as variações de tempetura reduzindo as amplitudes térmicas. Além disso, parte da radiação incidente é consumida nos processos metabólicos das plantas que aciona o mecanismo de evapotranspiração que, por sua vez, retira calor sensível do ambiente com a evaporação da água. A soma desses processos reduz a entrada e permanência do calor no ambiente ao mesmo tempo em que diminui a dissipação do baixo saldo radiativo para o ambiente e atmosfera durante a noite. 

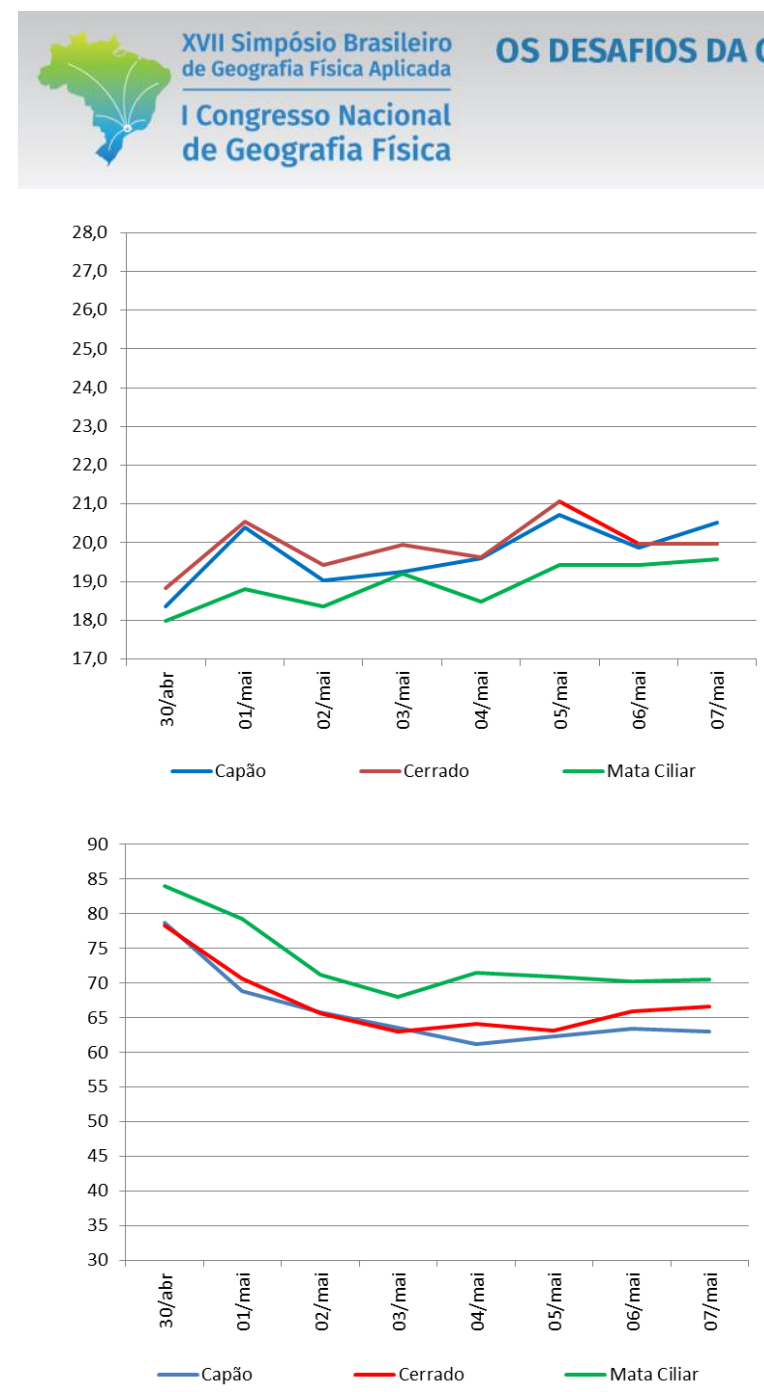
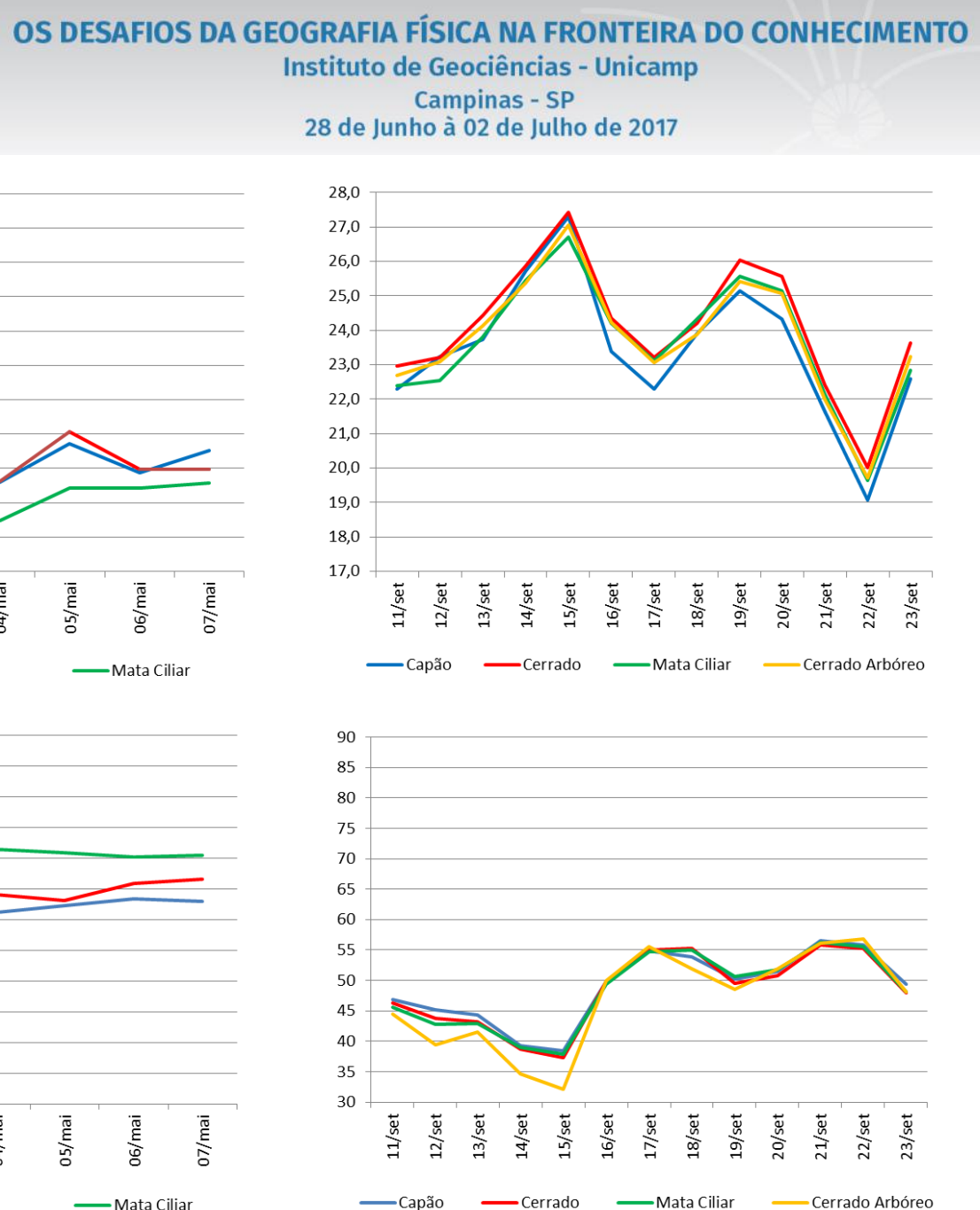

Figura 4 - Variação média diária da temperatura (acima) e umidade relativa do ar (abaixo): 30/04-07/05/2016 e 1123/09/2016. Elaboração: Carlos H. Jardim.

\section{Considerações Finais}

Apesar de situações locais diferenciadas é interessante comparar os dados obtidos no posto do cerrado com aqueles da estação do INMET no centro urbano de Belo Horizonte (Av. Raja Gabaglia com a Av. Contorno). Para o segmento temporal entre os dias 10 e 24/05/2016 os dados médios indicaram que o cerrado é mais frio $\left(24^{\circ} \mathrm{C}\right.$ no cerrado e $25,2^{\circ} \mathrm{C}$ em Belo Horizonte). Entretanto, ao comparar valores horários, principalmente no período da tarde, os valores de temperatura obtidos no cerrado mostram-se mais elevados em diversas ocasiões, sob condições atmosféricas semelhantes de tempo estável com pouca ou sem nebulosidade, caso do dia 15/09 às 15 h quanto foram registrados, simultaneamente, nos postos da Mata Ciliar 32,2 ${ }^{\circ} \mathrm{C}$, Cerrado 34, $8^{\circ} \mathrm{C}$, Cerrado Arbóreo 33, $1^{\circ} \mathrm{C}$, Capão 33,4 ${ }^{\circ} \mathrm{C}$, Belo Horizonte-Pampulha $33,4^{\circ} \mathrm{C}$, Belo Horizonte Av. Contorno-Raja $33,7^{\circ} \mathrm{C}$, Sete Lagoas 34,8 e Conceição do Mato Dentro 35, $7^{\circ}$ 
C. E não há indícios de que esse fator afete negativamente a vegetação de cerrado do parque. Pelo contrário, desde a criação do parque, as formações naturais de vegetação, incluindo o cerrado e a mata ciliar na área onde foram obtidos os dados, ganham cada vez mais espaço sobre antigas áreas de pastagens.

Trazendo essa questão para o planejamento urbano e conservação ambiental, isso significa que a vegetação deve ser vista sob um espectro variado de funções e não apenas visando atenuação do impacto térmico. A manutenção dos processos naturais e serviços ecológicos como a formação de solos, infiltração de água, preservação da biodiersidade etc., estão entre as funções primordiais da vegetação e sem os quais as socidades humanas não se desenvolveriam.

\section{Bibliografia}

AZEVEDO, T. R. Derivação antrópica do clima na Região Metropolitana de São Paulo abordada como função do ritmo semanal das atividades humanas. Tese (Doutorado). Departamento de Geografia - Faculdade de Filosofia, Letras e Ciências Humanas - Universidade de São Paulo. 2001.

BONAN, G. Ecological climatology: concepts and applications. 2.ed. New York: Cambridge Univesity Press, 2008.

FIGUEIREDO, J. M.; MONTEIRO, H. C.; LEAL, L. F. G.; ASSIS, W. L. Identificação e caracterização dos microclimas da porção oeste do Parque Nacional da Serra do Cipó (MG). In: XI Simpósio Brasileiro de Climatologia Geográfica, 2014, Curitiba. XI Simpósio Brasileiro de Climatologia Geográfica. Anais... Curitiba: UFPR, 2014. v. 1. p. $1072-1084$.

GEIGER, Rudolf. Manual de microclimatologia. O clima da camada de ar junto ao solo. 4a. ed. Lisboa: Fundação Calouste Gulbenkian, 1961.

GONTIJO, B. M. Uma geografia para a Cadeia do Espinhaço. Megadiversidade, vol. 4, n. 1-2, dez. 2008.

GOOGLE MAPS. Parque Nacional da Serra do Cipó. 2016. Disponível em: <https://www.google.com.br/maps/@-18.3595231,-43.8476088,340876m/data=!3m1!1e3!5m1!1e4>. Acesso em: 10 jun. 2016.

IBGE. Base Cartográfica Contínua do Brasil na escala de 1:250.000. Disponível em: <http://www.geoservicos.ibge.gov.br/>. Acesso em: 10 jun. 2016.

MACHADO, F. L. V.; NERY, F. H.; COELHO, J. P. R.; JARDIM, C. H. Aspectos do clima e paisagem em trecho do Parque Nacional da Serra do Cipó-MG: variações horárias de temperatura e umidade relativa do ar no período de 11 a 13/04/2014. In: XI Simpósio Brasileiro de Climatologia Geográfica (XI SBCG - IV SPEC - COC UGI MEETING): Variabilidade e mudanças climáticas: estado da arte e perspectivas da interação sociedade-natureza, 2014, Curitiba-PR. Anais... Curitiba: UFPR, 2014. v. 1. p. 272-283.

MACHADO, L. A.; GONCALVES, I.; MAGALHAES, M. A. N.; ASSIS, W. L. Análise do comportamento térmico e hígrico em área do Parque Nacional da Serra do Cipó. In: XI Simpósio Brasileiro de Climatologia Geográfica, 2014, Curitiba. Anais... Curitiba, UFPR, 2014. v.1. p. 449-460.

MMA-ICMBIO. Plano de Manejo: Parque Nacional da Serra do Cipó e Área de Proteção Ambiental Morro da Pedreira. Brasília: MMA, 2009.

MONTEIRO, C. A. F. Análise rítmica em climatologia. Problemas da atualidade climática em São Paulo e achegas para um programa de trabalho. Climatologia, São Paulo, n.1, p.1-21, 1971.

SAAD, A. A geomorfologia da Serra do Espinhaço em Minas Gerais e de suas margens. Geonomos, v.3, n.1, 1995. 


$\begin{gathered}\text { XVII Simpósio Brasileiro } \\ \text { de Geografia Fisica Aplicada }\end{gathered}$
$\begin{aligned} & \text { I Congresso Nacional } \\ & \text { de Geografia Física }\end{aligned}$

TARIFA, J. R.; ARMANI, G. Os climas "naturais”. In: TARIFA, J. R.; AZEVEDO, T. R. (Orgs.) Os climas na cidade de São Paulo: teoria e prática. São Paulo: Pró-Reitoria de Cultura e Extensão. Universidade de São Paulo: Laboratório de Climatologia. Faculdade de Filosofia, Letras e Ciências Humanas. Universidade de São Paulo, 2001. Cap. 2. p. 34-46. (Geousp - Coleção Novos Caminhos, 4).

TARIFA, J. R. Os climas nos maciços litorâneos da Juréia-Itatins: um ensaio de ritmanálise. Tese (Livre Docência). Faculdade de Filosofia, Letras e Ciências Humanas, Universidade de São Paulo, São Paulo, 2002. 